\title{
Content Characteristics of Rare Earth Elements in Stone Coal and Parting in Southern Shaanxi, China
}

\author{
Weiguo Zhang ${ }^{1,2,3}$, Jianye Yang ${ }^{4}$, Yuan Shis, Tingting Lv², Mengmeng Fan ${ }^{1}$ \\ ${ }^{1}$ College of Geology and Environment, Xi'an University of Science and Technology, Xi'an, China \\ ${ }^{2}$ Key Laboratory of Coal Resources Exploration and Comprehensive Utilization, Ministry of Land and Resources, \\ Xi'an, China \\ ${ }^{3}$ Geological Research Institute for Coal Green Mining, Xi'an University of Science and Technology, Xi'an, China \\ ${ }^{4}$ College of Materials Science and Engineering, Xi'an University of Science and Technology, Xi'an, China \\ ${ }^{5}$ Shanxi Academy of Analytical Sciences, Taiyuan, China \\ Email: zhangwg0224@163.com
}

How to cite this paper: Zhang, W.G., Yang, J.Y., Shi, Y., Lv, T.T. and Fan, M.M. (2019) Content Characteristics of Rare Earth Elements in Stone Coal and Parting in Southern Shaanxi, China. International Journal of Clean Coal and Energy, 8, 1-13. https://doi.org/10.4236/ijcce.2019.81001

Received: January 27, 2019

Accepted: February 25, 2019

Published: February 28, 2019

Copyright ( 2019 by author(s) and Scientific Research Publishing Inc. This work is licensed under the Creative Commons Attribution International License (CC BY 4.0).

http://creativecommons.org/licenses/by/4.0/ c) (i) Open Access

\begin{abstract}
Stone coal is a special resource, because it is associated with a variety of rare metal elements. The elemental geochemical characteristics of stone coal can provide useful information for the study of its formation and evolution history. The content of rare earth elements in stone coal has been the focus of attention. Stone coal is widely distributed in southern Shaanxi province of China. In order to study the content and distribution of rare earth elements in stone coal, and provide a plan for the comprehensive development and utilization of stone coal, this study tested the rare earth elements content of stone coal, parting and coal ash samples, respectively, compared the content of rare earth elements in stone coal, parting, coal ash with the mean value of China coal, the mean value of world coal and the abundance value of upper crust, and discussed the features of rare earth elements content in different types of samples in southern Shaanxi province of China. The average contents of rare earth elements in the samples of stone coal, parting and coal ash were calculated, and the enrichment coefficients of the samples with the mean value of China coal, the mean value of world coal and the abundance value of upper crust were listed. The distribution rules and characteristics of the contents of rare earth elements in different types of samples in southern Shaanxi province of China were summarized.
\end{abstract}

\section{Keywords}

Stone Coal, Rare Earth Elements, Characteristics, Geochemical 


\section{Introduction}

Stone coal is a kind of inferior sapropelite which is formed in ancient strata. It has the characteristics of high ash, high sulfur, low carbon content, low calorific value, accompanying many kinds of metal elements and so on [1] [2] [3]. China's stone coal resources are widely distributed and have rich reserves, which cover more than 20 provinces and regions, and the amount of stone coal in southern Qinling Mountain is the most [4]. Ankang City is located in the southern part of Shaanxi Province, south of Qinling Mountain and north of Bashan Mountain. It is famous for the existence of stone coal resources (Figure 1), and it belongs to the North Daba Mountain fold system of Kunlun Qinling tectonic belt [5]. The stone coal of Ankang is mainly distributed in the Cambrian system of Hanbin district, Ziyang county, Langao county, Pingli county and Zhenping county and Silurian system. The available stone coal reserves in southern Shaanxi are more than 300 million ton [6] [7] [8], which can guarantee the comprehensive utilization of 3 million t stone coal projects for more than 100 years. The stone coals of southern Shaanxi contain vanadium, molybdenum, uranium, selenium, gallium, phosphorus, silver, zinc, copper, cadmium, cobalt, platinum, lead, palladium, nickel, yttrium and so on [9] [10] [11] [12]. And the purity of vanadium is generally high, which can reach the value of exploitation; the next ones are molybdenum, uranium, phosphorus, silver and other elements [13].

Luo et al. have counted the selenium content in the lower Cambrian Lujiaping formation $(41.0 \mu \mathrm{g} / \mathrm{g})$, the Jianzhuba formation $(18.5 \mu \mathrm{g} / \mathrm{g})$ and the Lower Silurian Daguiping formation $(14.0 \mu \mathrm{g} / \mathrm{g})$ in the southern Qinling Mountains [9] [10] [14]. They consider that the hot magma of early Cambrian system volcanic

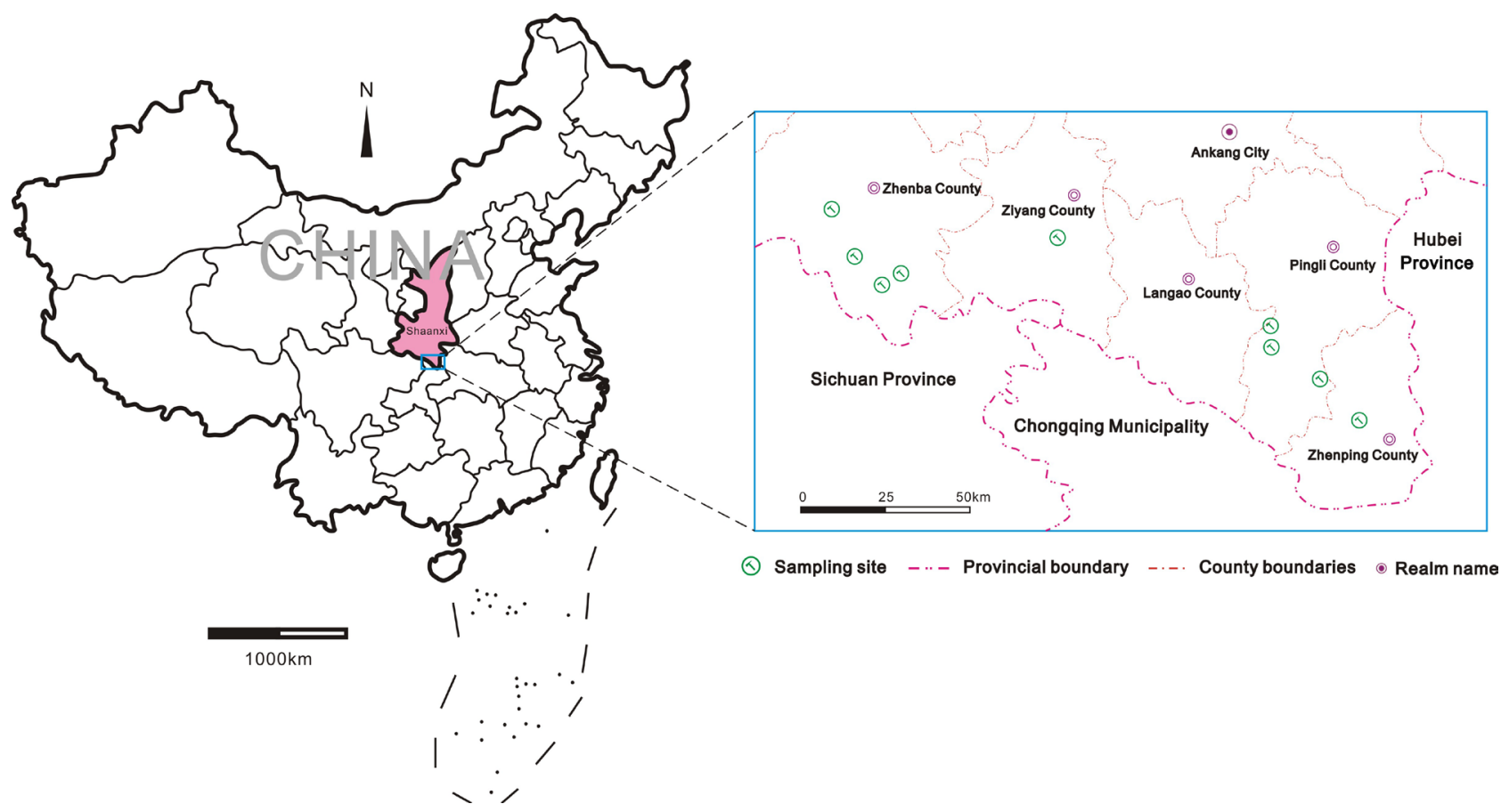

Figure 1. The sampling point distribution diagram. 
activity is the main source of selenium element in the stone coal, and the main factor is the adsorption of organic matter and clay [9]. Hu et al. [15], Tang et al. [16], Tang [17] and Li et al. [18] tested for arsenic content in stone coal of southern Shaanxi, and the results showed that arsenic content in stone coal was much higher than that in Chinese coal [19]. Chen et al. [20] found that the highest fluorine content of stone coal in Daba Mountain and parts of Qinling Mountains was $4688.0 \mu \mathrm{g} / \mathrm{g}$, which led to the prevalence of fluorosis. To sum up, the trace element geochemistry of stone coal in southern Shaanxi mainly concentrates on the statistics of vanadium, selenium, fluorine, arsenic and other elements. The source of the above elements, the state of occurrence, and the environmental effect and so on are analyzed. The study of rare earth elements in southern Shaanxi stone coal is relatively weak [21].

Due to their stable chemical properties and high degree of homogenization, there are rare earth elements often hidden with some geological evolution information and considered as good geochemical indicators, which have always been the focus of geochemical research [22] [23]. There are few reports on the REE contents, distribution patterns and geochemical characteristics of $\delta \mathrm{Ce}$ and $\delta \mathrm{Eu}$ in stone coals of southern Shaanxi province. This study aims to explore the characteristics of rare earth elements in stone coal of southern Shaanxi, and provide a plan for the comprehensive utilization of stone coal.

\section{Sample Collection and Experiment}

Stone coal mining in southern Shaanxi has a long history [24] [25]. The samples were collected from Ankang City and Hanzhong City of Shaanxi Province and distributed in Zhenping County, Pingli County, Ziyang County and Zhenba County in this research (Figure 1). Sample YLEW was collected from Yulaoerwan Coal Mine in Zhenping County, sample BX was collected from Baxian Coal Mine in Pingli County, sample YDH was collected from Yuduhe Coal Mine in Pingli County, sample HYL was collected from Hualing Village of Baxian Town, Pingli County, and sample XCY was collected from Xiaoteyuan Village of Huoxi Township in Ziyang County. Sample YJB was collected from Yuanjiaba Coal Mine in Zhenba County, sample AJS was collected from Anjiashan Coal Mine in Zhenba County, sample BSX was collected from Baishuixi Coal Mine in Zhenba County, and sample RCX was collected from Rencun Xiang Coal Mine in Zhenba County. In this study, three types of samples were collected: “-C" for coal, "-P" for parting and "-A" for coal ash. The sample was condensed according to the method of four fractions of pile cones, and one sample was broken and ground in order to make the particle size of the sample was less than 200 mesh. Determination of rare earth elements in stone coal by microwave digestion and inductively coupled plasma mass spectrometer (Table 1).

\section{Content Characteristics of Rare Earth Elements}

\subsection{Content Characteristics of REEs in Stone Coal}

The REEs contents of XCY-C $(179.81 \mu \mathrm{g} / \mathrm{g})$ was higher than that of the mean 
Table 1. The rare earth element content $(\mu \mathrm{g} / \mathrm{g})$ and related parameters of stone coal and parting from southern Shaanxi province, China.

\begin{tabular}{|c|c|c|c|c|c|c|c|c|c|c|c|c|c|c|c|c|c|c|c|}
\hline Sample & $\mathrm{La}$ & $\mathrm{Ce}$ & $\operatorname{Pr}$ & $\mathrm{Nd}$ & Sm & $\mathrm{Eu}$ & $\mathrm{Gd}$ & $\mathrm{Tb}$ & Dy & $\mathrm{Y}$ & Ho & Er & $\mathrm{Tm}$ & $\mathrm{Yb}$ & $\mathrm{Lu}$ & $\Sigma \mathrm{REE}$ & $\Sigma$ LREE & $\Sigma$ HREE & $\mathrm{L} / \mathrm{H}$ \\
\hline $\mathrm{XCY}-\mathrm{C}$ & 25.70 & 35.30 & 5.83 & 26.00 & 5.43 & 1.25 & 6.30 & 0.94 & 5.99 & 57.50 & 1.37 & 4.17 & 0.54 & 3.06 & 0.43 & 179.81 & 99.51 & 80.30 & 1.24 \\
\hline XCY-A & 51.30 & 71.70 & 11.40 & 50.80 & 10.50 & 2.49 & 12.00 & 1.78 & 11.40 & 109.00 & 2.57 & 7.78 & 1.01 & 5.62 & 0.77 & 350.12 & 198.19 & 151.93 & 1.30 \\
\hline HYL-C & 15.30 & 20.60 & 3.74 & 16.90 & 3.80 & 0.90 & 4.01 & 0.56 & 3.37 & 25.80 & 0.73 & 2.23 & 0.32 & 2.03 & 0.32 & 100.61 & 61.24 & 39.37 & 1.56 \\
\hline HYL-A & 25.30 & 33.50 & 6.27 & 28.60 & 6.41 & 1.55 & 6.81 & 0.96 & 5.76 & 44.60 & 1.24 & 3.64 & 0.50 & 3.07 & 0.47 & 168.68 & 101.63 & 67.05 & 1.52 \\
\hline YDH-C & 3.98 & 5.55 & 0.73 & 3.00 & 0.62 & 0.15 & 0.68 & 0.10 & 0.61 & 4.77 & 0.14 & 0.41 & 0.06 & 0.36 & 0.06 & 21.21 & 14.03 & 7.18 & 1.95 \\
\hline YDH-P & 11.40 & 18.90 & 2.16 & 7.97 & 1.56 & 0.34 & 1.41 & 0.20 & 1.16 & 6.88 & 0.23 & 0.71 & 0.10 & 0.64 & 0.10 & 53.76 & 42.33 & 11.43 & 3.70 \\
\hline $\mathrm{BX}-\mathrm{C}$ & 5.46 & 7.58 & 1.25 & 5.64 & 1.22 & 0.30 & 1.34 & 0.20 & 1.26 & 10.60 & 0.28 & 0.86 & 0.12 & 0.73 & 0.11 & 36.95 & 21.45 & 15.50 & 1.38 \\
\hline YLEW-C & 6.55 & 9.01 & 1.55 & 6.81 & 1.46 & 0.49 & 1.68 & 0.25 & 1.58 & 13.10 & 0.35 & 1.09 & 0.15 & 0.96 & 0.15 & 45.18 & 25.87 & 19.31 & 1.34 \\
\hline RCX-C & 2.52 & 4.70 & 0.47 & 1.73 & 0.34 & 0.07 & 0.33 & 0.05 & 0.28 & 1.67 & 0.05 & 0.16 & 0.02 & 0.14 & 0.02 & 12.55 & 9.83 & 2.72 & 3.61 \\
\hline RCX-P & 13.80 & 28.00 & 3.17 & 12.70 & 2.54 & 0.56 & 2.29 & 0.30 & 1.66 & 9.22 & 0.32 & 0.93 & 0.13 & 0.89 & 0.13 & 76.64 & 60.77 & 15.87 & 3.83 \\
\hline YJB-C & 3.30 & 6.52 & 0.69 & 2.60 & 0.59 & 0.12 & 0.59 & 0.09 & 0.57 & 3.76 & 0.12 & 0.33 & 0.05 & 0.32 & 0.04 & 19.69 & 13.82 & 5.87 & 2.35 \\
\hline YJB-P & 26.00 & 53.00 & 5.75 & 20.70 & 3.78 & 0.76 & 3.05 & 0.41 & 2.23 & 11.40 & 0.44 & 1.29 & 0.22 & 1.26 & 0.19 & 130.48 & 109.99 & 20.49 & 5.37 \\
\hline AJS-C & 6.08 & 11.20 & 1.26 & 4.76 & 0.96 & 0.21 & 0.87 & 0.13 & 0.83 & 4.51 & 0.17 & 0.52 & 0.08 & 0.54 & 0.08 & 32.20 & 24.47 & 7.73 & 3.17 \\
\hline AJS-P & 16.10 & 33.20 & 3.56 & 13.10 & 2.33 & 0.46 & 1.70 & 0.21 & 1.11 & 5.59 & 0.23 & 0.72 & 0.11 & 0.79 & 0.12 & 79.33 & 68.75 & 10.58 & 6.50 \\
\hline BSX-C & 21.50 & 43.60 & 4.65 & 16.50 & 2.79 & 0.53 & 2.18 & 0.30 & 1.77 & 10.00 & 0.38 & 1.15 & 0.19 & 1.20 & 0.18 & 106.92 & 89.57 & 17.35 & 5.16 \\
\hline BSX-P & 25.80 & 52.00 & 6.15 & 23.00 & 4.69 & 0.90 & 3.71 & 0.49 & 2.68 & 14.70 & 0.51 & 1.52 & 0.22 & 1.49 & 0.22 & 138.08 & 112.54 & 25.54 & 4.41 \\
\hline AVGC & 10.04 & 16.01 & 2.24 & 9.33 & 1.91 & 0.45 & 2.00 & 0.29 & 1.81 & 14.63 & 0.40 & 1.21 & 0.17 & 1.04 & 0.15 & 61.68 & 39.98 & 21.70 & 1.84 \\
\hline AVGA & 38.30 & 52.60 & 8.84 & 39.70 & 8.46 & 2.02 & 9.41 & 1.37 & 8.58 & 76.80 & 1.91 & 5.71 & 0.76 & 4.35 & 0.62 & 259.40 & 149.91 & 109.49 & 1.37 \\
\hline China $\mathrm{C}^{\mathrm{a}}$ & 22.50 & 46.70 & 6.42 & 22.30 & 4.07 & 0.84 & 4.65 & 0.62 & 3.74 & 18.20 & 0.96 & 1.79 & 0.64 & 2.08 & 0.38 & 135.89 & 102.83 & 33.06 & 3.11 \\
\hline World $C^{b}$ & 11.00 & 23.00 & 3.50 & 12.00 & 2.00 & 0.47 & 2.70 & 0.32 & 2.10 & 8.40 & 0.54 & 0.93 & 0.31 & 1.00 & 0.20 & 68.47 & 51.97 & 16.50 & 3.15 \\
\hline $\mathrm{UCC}^{\mathrm{c}}$ & 30.00 & 64.00 & 7.10 & 26.00 & 4.50 & 0.88 & 3.80 & 0.64 & 3.50 & 22.00 & 0.80 & 2.30 & 0.33 & 2.20 & 0.32 & 168.37 & 132.48 & 35.89 & 3.69 \\
\hline
\end{tabular}

${ }^{a}$ China coals, data from Dai et al. (2012) [19]; ${ }^{b}$ World coals, data from Ketris and Yudovich (2009) [26]; 'Upper crust continental, data from Taylor and McLennan (1985) [27]. L/H = (LREE/HREE).

value of China coal $(135.89 \mu \mathrm{g} / \mathrm{g})$, the content of light rare earth elements $(99.51$ $\mu \mathrm{g} / \mathrm{g})$ is slightly lower than the mean value of light rare earth elements (102.83 $\mu \mathrm{g} / \mathrm{g})$ in China coal $(102.83 \mu \mathrm{g} / \mathrm{g})$. The content of heavy rare earth elements $(80.30 \mu \mathrm{g} / \mathrm{g})$ was higher than the mean value of heavy rare earth elements in China coal $(33.06 \mu \mathrm{g} / \mathrm{g})$, the ratio of light and heavy rare earth elements is quite different. The content of $\mathrm{Y}$ is 2 times higher than that of in China coal, which is the main reason for the high content of heavy rare earth elements. Compared with the mean value of world coal, the rare earth elements in XCY-C stone coal samples are obviously enriched, which is twice that of the mean value of world coal $(68.47 \mu \mathrm{g} / \mathrm{g})$, and the heavy rare earth element content is 5 times that of the mean value of world coal $(16.50 \mu \mathrm{g} / \mathrm{g})$. The REEs content of XCY-C coal samples is close to the abundance value of upper crust $(168.37 \mu \mathrm{g} / \mathrm{g})$, and it also shows 
that the light rare earth elements content is lower than the abundance value of upper crust $(132.48 \mu \mathrm{g} / \mathrm{g})$, and the heavy rare earth elements are higher than that of upper crust $(35.89 \mu \mathrm{g} / \mathrm{g})$. The HYL-C, YDH-C and BX-C are collected from Pingli County, these contents of rare earth elements differ greatly among the three samples $(21.21 \mu \mathrm{g} / \mathrm{g}-100.61 \mu \mathrm{g} / \mathrm{g})$. The REEs contents of HYL-C (100.61 $\mu \mathrm{g} / \mathrm{g}$ ) is higher than that of the mean value of world coal, lower than that of the mean value of China coal and the abundance value of upper crust, the REEs contents of YDH-C $(21.21 \mu \mathrm{g} / \mathrm{g})$ and BX-C $(36.95 \mu \mathrm{g} / \mathrm{g})$ are much lower than the mean value of China coal, the mean value of world coal and the abundance value of upper crust, it shows that the REEs is seriously depleted. The REEs contents of $(45.18 \mu \mathrm{g} / \mathrm{g})$ of YLEW-C is much lower than that of the mean value of China coal, the mean value of world coal and the abundance value of upper crust, and the depletion of rare earth elements are serious. The RCX-C, YJB-C, AJS-C and BSX-C were collected from Zhenba County, and the contents of rare earth elements in the four samples vary greatly. The contents of rare earth elements of BSX-C $(106.92 \mu \mathrm{g} / \mathrm{g})$ is higher than that of the mean value of world coal, lower than that of the mean value of China coal and the abundance value of upper crust. The contents of rare earth elements in RCX-C (12.55 $\mu \mathrm{g} / \mathrm{g})$, YJB-C (19.69 $\mu \mathrm{g} / \mathrm{g})$ and AJS-C $(32.20 \mu \mathrm{g} / \mathrm{g})$ are far lower than the mean value of China coal, the mean value of world coal and the abundance value of upper crust. The contents of rare earth elements in stone coal in southern Shaanxi is generally lower than the mean value of China coal and the abundance value of upper crust, which is close to the mean value of world coal, and it shows the characteristics of serious REEs loss and uneven distribution in general with large regional differences (Table 1).

\subsection{Content Characteristics of REEs in Parting}

The contents of rare earth elements $(53.76 \mu \mathrm{g} / \mathrm{g})$ in the parting of YDH-P are close to the mean value of world coal. Compared with the corresponding stone coal bed (YDH-C), the contents of rare earth elements increased obviously about 2 times. The ratio of light and heavy rare earth elements varies greatly, showing that light rare earth elements are more enriched in parting. The contents of rare earth elements $(290.87 \mu \mathrm{g} / \mathrm{g})$ in YLEW-P is obviously higher than that the mean value of China coal, the mean value of world coal and the abundance value of upper crust, which is 4.25 times of the mean value of world coal and 6.44 times of the corresponding YLEW-C. Especially, the contents of light rare earth elements $(271.10 \mu \mathrm{g} / \mathrm{g})$ were obviously enriched, and the ratio of light rare earth elements to heavy rare earth elements reached 13.71. The contents of rare earth elements in the four parting samples of RCX-P, YJB-P, AJS-P and BSX-P vary greatly $(76.64 \mu \mathrm{g} / \mathrm{g}-138.08 \mu \mathrm{g} / \mathrm{g})$. Compared with the corresponding stone coal bed (RCX-C, YJB-C, AJS-C, BSX-C), the contents of REE increased 6.11 times, 6.63 times, 2.46 times and 1.29 times of the corresponding coal seam respectively. The ratio of heavy and light rare earth elements increase, it shows that the 
light rare earth elements in the parting samples are more enriched. The contents of rare earth elements in parting in southern Shaanxi is generally higher than that in corresponding stone coal seam (Table 1).

\subsection{Content Characteristics of REEs in Coal Ash}

The samples of XCY-C and HYL-C were selected and the samples of stone coal were incinerated at $815^{\circ} \mathrm{C}$. Then the contents of rare earth elements in the combustion products were determined. The enrichment of rare earth elements ( $350.12 \mu \mathrm{g} / \mathrm{g}$ and $168.68 \mu \mathrm{g} / \mathrm{g}$ ) in coal ash are higher than that the mean value of China coal, the mean value of world coal and the abundance value of upper crust (Table 1). The enrichment ratio of rare earth elements in coal ash and raw coal samples are defined as the enrichment ratio. There are found that the enrichment ratios of light and heavy rare earth elements are close to each other. The ash yield (44.16\% and 51.56\%) was smaller than that of the corresponding raw coal (Figure 2). The enrichment of rare earth elements in coal ash indicates that the rare earth elements in stone coal samples mainly exist in inorganic materials. The similar enrichment ratios indicate that the rare earth elements are light, the heavy rare earth elements exist in the same state and the differentiation degree is close to each other.

\subsection{The Average Content Characteristics of REEs in Stone Coal, Parting, and Coal Ash}

In order to better summarize the content characteristics of rare earth elements in stone coal, parting and coal ash in southern Shaanxi, China. The samples were classified and averaged. The results are shown in Table 1. AVGC is the average value of stone coal samples, AVGP is the average value of parting samples, and AVGA is the average value of coal ash samples. The average value of rare earth elements in stone coal, parting and coal ash samples was divided by the mean value of China coal, the mean value of world coal and the abundance value of

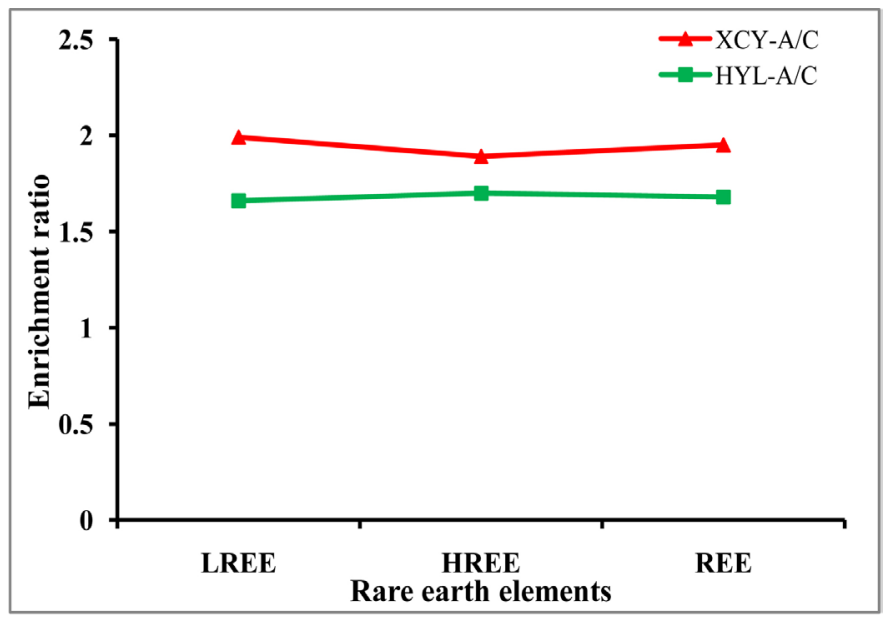

Figure 2. The enrichment ratio of rare earth elements in coal ash and raw coal. 
upper crust, and the corresponding enrichment coefficient was obtained (Figures 3-11).

According to the enrichment coefficient, compared with the mean value of China coal, the content of rare earth elements in stone coal is lower than the mean value of China coal (0.26 - 0.80) (Figure 3). Compared with the mean value of world coal, all light rare earth elements and most heavy rare earth elements are lower than the mean value of world coal, $\mathrm{Y}, \mathrm{Er}$ and $\mathrm{Yb}$ are higher than the mean value of world coal. $\mathrm{Y}$ is 1.74 times of the mean value of world coal (Figure 4). Compared with the abundance value of upper crust, all the rare earth elements were lower than the abundance value of upper crust (0.25 - 0.67), and the light rare earth loss was higher than the heavy rare earth loss (Figure 5).

Compared with the mean value of China coal, the contents of all heavy rare earth elements in parting samples are lower than the mean value of China coal (0.23 - 0.68), half of light rare earth elements are higher than the mean value of China coal, La, Ce and Sm are higher than the mean value of China coal, and $\mathrm{Pr}$,

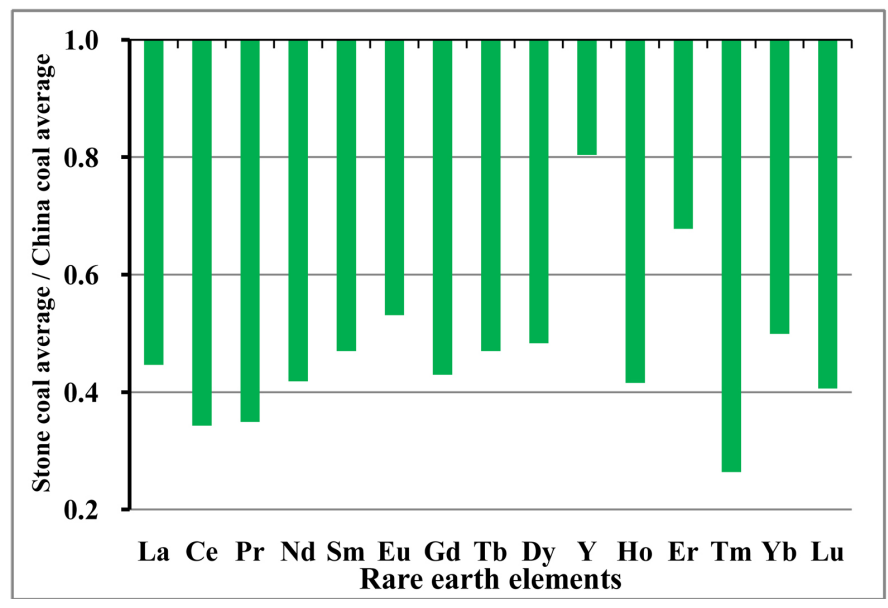

Figure 3. The ratio of the average of rare earth elements content in stone coal and China coal.

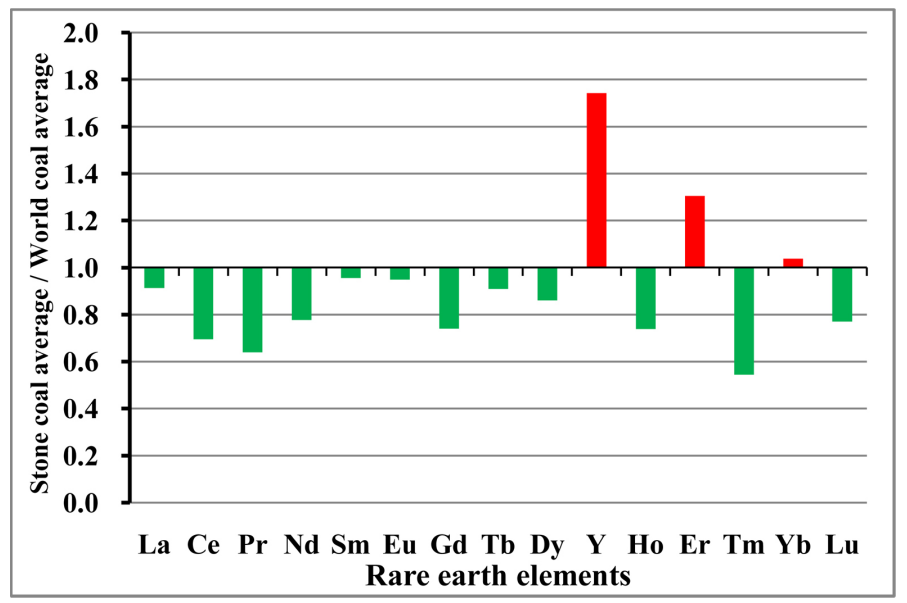

Figure 4. The ratio of the average of rare earth elements content in stone coal and world coal. 


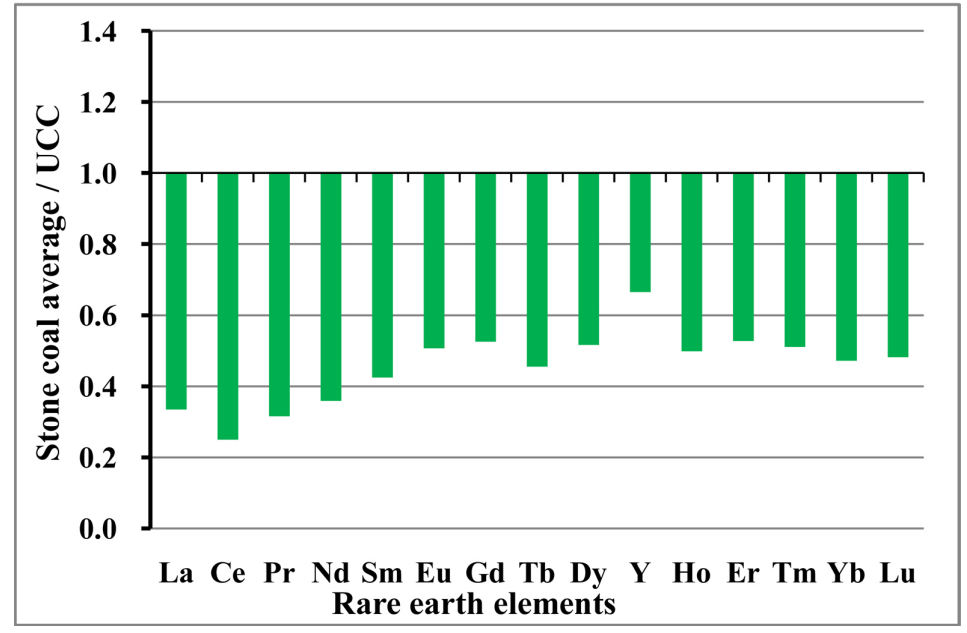

Figure 5. The ratio of the average of rare earth elements content in stone coal and UCC.

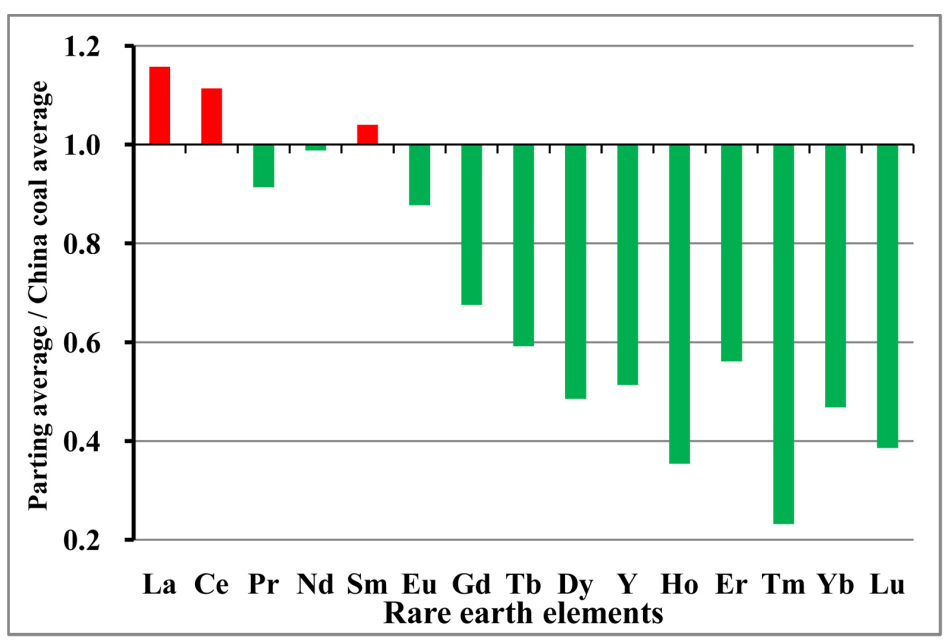

Figure 6. The ratio of the average of rare earth elements content in parting and China coal.

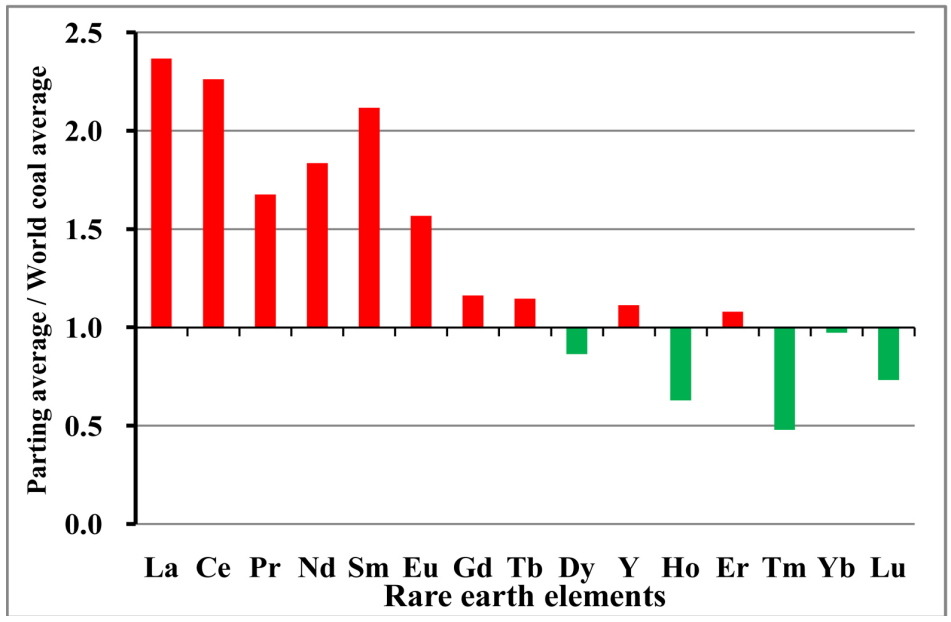

Figure 7. The ratio of the average of rare earth elements content in parting and world coal. 


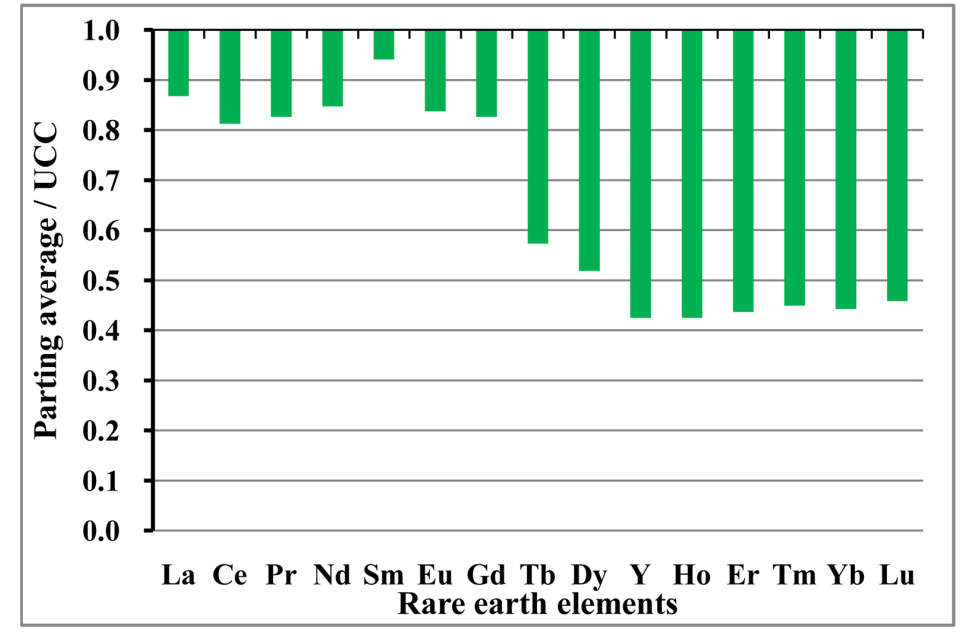

Figure 8. The ratio of the average of rare earth elements content in parting and UCC.

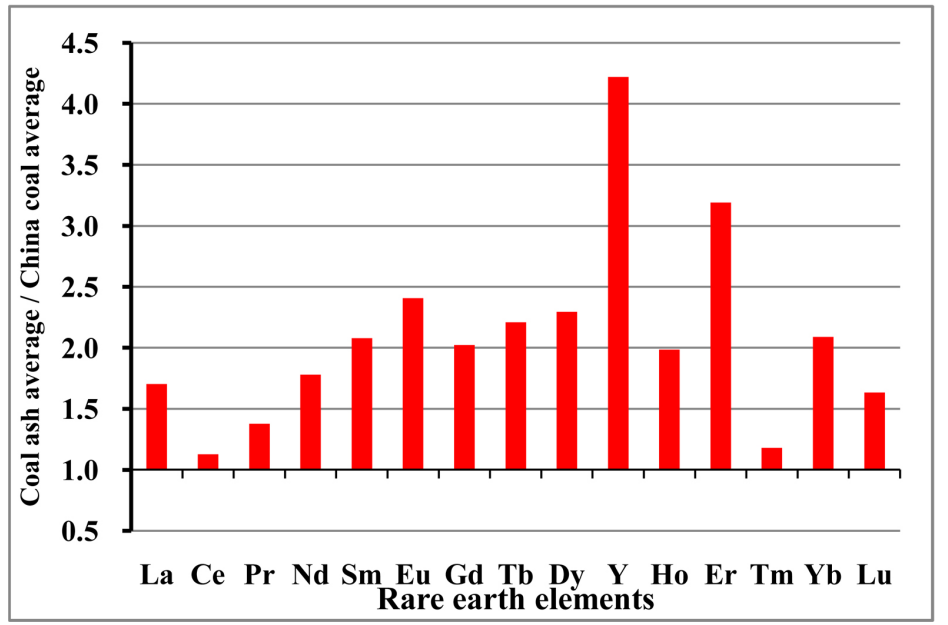

Figure 9. The ratio of the average of rare earth elements content in coal ash and China coal.

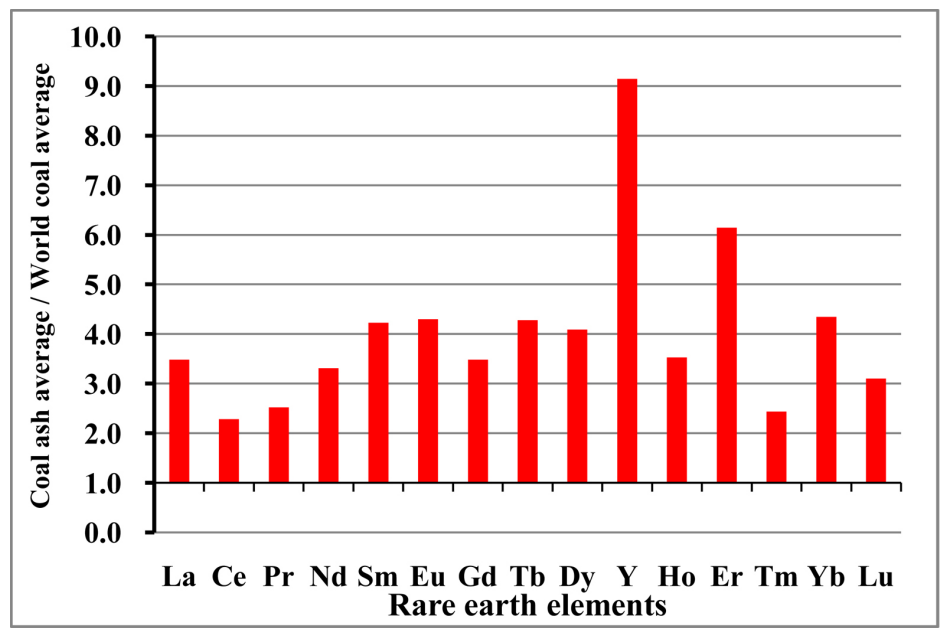

Figure 10. The ratio of the average of rare earth elements content in coal ash and world coal. 


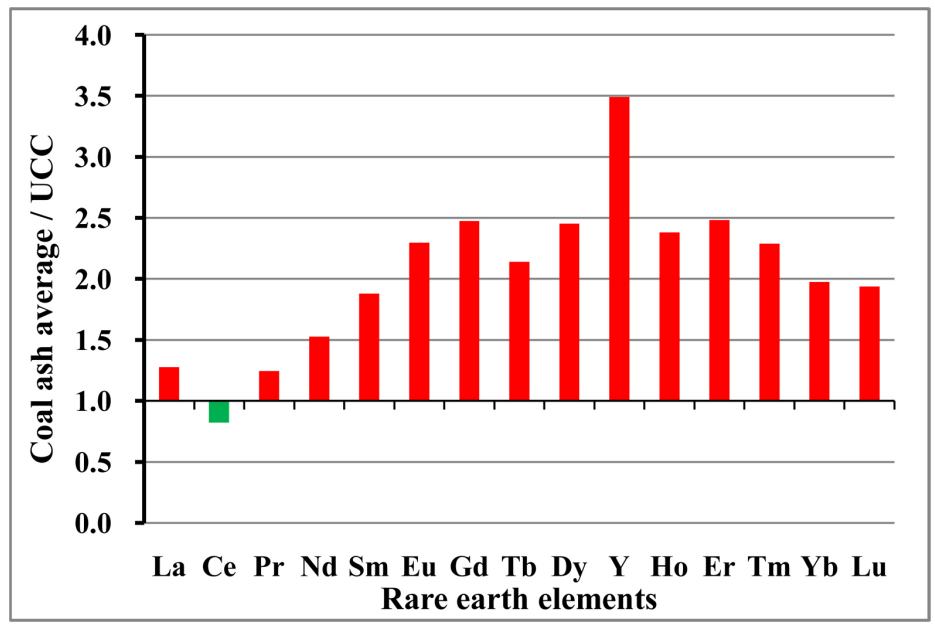

Figure 11. The ratio of the average of rare earth elements content in coal ash and UCC.

$\mathrm{Nd}$ and $\mathrm{Eu}$ are lower than the mean value of China coal (Figure 6). Compared with the mean value of world coal, all light rare earth elements are higher than the mean value of world coal (1.57 - 2.37), half of heavy rare earth elements are lower than the mean value of world coal, Gd, Tb, Y and Er are higher than the mean value of world coal, Dy, Ho, Tm and Lu are lower than the mean value of world coal (Figure 7). Compared with the abundance value of upper crust, all soil elements were lower than the abundance value of upper crust (0.42 - 0.94), and the heavy rare earth loss was higher than the light rare earth loss (Figure 8).

Compared with the mean value of China coal, the content of all rare earth elements in coal ash is higher than the mean value of China coal (1.18 - 4.22). The average content of 8 elements $(\mathrm{Sm}, \mathrm{Eu}, \mathrm{Gd}, \mathrm{Tb}, \mathrm{Dy}, \mathrm{Y}, \mathrm{Er}$ and $\mathrm{Yb}$ ) is more than twice that of the mean value of China coal, with Er reaching 3.19 times and Y 4.22 times (Figure 9). Compared with the mean value of world coal, all rare earth elements are higher than the mean value of world coal (2.29-9.14), and the average content of 6 elements ( $\mathrm{Sm}, \mathrm{Eu}, \mathrm{Tb}, \mathrm{Dy}, \mathrm{Y}, \mathrm{Er}$ and $\mathrm{Yb}$ ) is more than 4 times of the mean value of world coal, in which $\mathrm{Er}$ is 6.14 times and $\mathrm{Y}$ is 9.14 times (Figure 10). Compared with the abundance value of upper crust, except for $\mathrm{Ce}$, the other rare earth elements were all higher than the abundance value of upper crust (1.24 - 3.49), and the enrichment degree of heavy rare earth elements was higher than that of light rare earth elements, especially Y element, which was 3.49 times of the abundance value of upper crust (Figure 11).

\section{Conclusion}

Southern Shaanxi is a well known stone coal occurrence area in China. Stone coal is widely distributed and abundant in reserves. There are a variety of rare metal elements (V, Mo, Ga, etc.) associated with stone coal. However, the content of rare earth elements in stone coal is not high, which is generally lower than the mean value of China coal. Compared with the mean value of world coal, light rare earth elements are lower than the mean value of world coal, and 
$\mathrm{Y}, \mathrm{Er}$ and $\mathrm{Yb}$ heavy rare earth elements are higher than the mean value of world coal. Compared with the abundance value of upper crust, all the rare earth elements are lower than the abundance value of upper crust, showing that the light rare earth deficit is higher than the heavy rare earth deficit. The low content of rare earth elements in stone coal indicates that the supply of rare earth elements in the source area is limited, and the rare earth elements are constantly lost during the evolution of coal seams. The rare earth elements are obviously more abundant in the parting than in the corresponding coal seam, generally about 2 - 6 times. This phenomenon implies that different sedimentary environments are the main factors that lead to the increase of rare earth elements, and the formation environment of parting is more conducive to the enrichment of rare earth elements. Rare earth elements were significantly enriched in coal ash, which was higher than the mean value of China coal, the mean value of world coal and the abundance value of upper crust. The enrichment of rare earth elements in coal ash indicates that the rare earth elements in stone coal samples are mainly found in inorganic materials. The similar enrichment ratio indicates that the occurrence of light and heavy rare earth elements is the same and the differentiation degree is similar.

\section{Acknowledgements}

This work was supported by the National Natural Science Foundation of China [No. 41802187] and [No. 41672145], the scientific research program funded by Shaanxi provincial education department [No. 18JK0521], and the program of geological research institute for coal green mining of XUST (Xi'an University of Science and Technology) [No. MTy 2019-09].

\section{Conflicts of Interest}

The authors declare no conflicts of interest regarding the publication of this paper.

\section{References}

[1] Jiang, Y.H., Yue, W.Z. and Ye, Z.Z. (1994) Characteristics, Sedimentary Environment and Origin of the Lower Cambrian Stone-Like Coal in Southern China. Coal Geology of China, No. 4, 26-31.

[2] Ren, D.Y., Zhao, F.H. and Dai, S.F. (2006) Trace Element Geochemistry of Coal. Science Press, Beijing, 1-556.

[3] Liu, Z.X., Dai, H.Z., Liu, J. and Ge, Z. (2016) Suggestions and Current Situation of Exploration, Development and Utilization of Stone-Coal Resources in China. China Mining Magazine, 25, 18-21.

[4] Geology Research Institute of Geology Prospection Branch, Coal Science Academy (GRI-CSA) (1982) Comprehensive Investigation Report of Stone Coal Resources in Southern China. 254 p. (In Chinese)

[5] Zhang, G.W., Meng, Q.R. and Lai, S.C. (1995) Structural and Structure of the Qinling Orogenic Belt. Chinese Science (B), 25, 994-998.

[6] Chen, X.M., Ma, H.C., Wei, D., Gao, G.S., Liu, H.B., Wang, F.X. and Huang, Z.X. 
(2010) Ankang Stone Coal Resources Exploration and Envelopment. Geology of Shaanxi, 28, 1-5+81.

[7] Wang, G.X. (2012) Ankang Will Become the "Panzhihua" of Shaanxi-Investigation on Comprehensive Utilization and Exploitation of Stone Coal Resources in Southern Shaanxi. Modern Enterprise, No. 8, 26-27.

[8] Yang, X.C. and Ma, H.C. (2013) Thought on the Characteristics and Comprehensive Utilization of Stone Coal. Shaanxi Coal, 32, 11-13.

[9] Luo, K.L. and Jiang, J.S. (1995) Selenium Content and Enrichment Law of the Lower Cambrian Strata in Ziyang and Langao, Shaanxi. Geology Geochemistry, No. 1, 68-71.

[10] Luo, K.L., Tan, J.N., Wang, W.Y., Xiang, L.H. and Li, D.Z. (2002) Chemical Mobility of Selenium in Early Paleozoic Rock and Stone Coal in Daba Mountain, South Qinling. Journal of Environmental Science, No. 1, 86-91.

[11] Tang, L., Yu, J.P. and Ji, H.B. (2008a) The Study on the Mode of Occurrence of Arsenic in Stone-Coal of Shaanxi. Journal of Capital Normal University (Natural Sciences Edition), No. 5, 85-88.

[12] Liu, Z.P., Mi, S., Li, Y.J., Cao, Z.J. and Yang, L.Q. (2017) Investigation and Analysis on Radioactivity Level of Bone-Coal Mine in Shaanxi Province. Uranium Geology, 33, 314-320.

[13] Wang, L., Zhang, Q.P. and Sun, W. (2017) Research on Occurrence of Vanadium in Stone Coal Deposit at Shangluo City, Shaanxi Province, China. Journal of Mineralogy, 37, 29-35.

[14] Luo, K.L., Zan, S.Q. and Zhang, M.S. (1995) Enrichment of Selenium in Stone Coal in South Qinling Mountain and Its Significance. Journal of Jilin University, No. 2, 125-130.

[15] Hu, Y.S., Cao, W.F., Liu, J. and Ke, Z.Z. (2003) Epidemiological Research of Coal-Burning Pollution Arseniasis and the Level of Arsenical in Environment in South of Shaanxi Province. Chinese Journal of Endemic Diseases, No. 4, 47-49.

[16] Tang, W.C., Li, D.W. and Liang, J.B. (2004) Investigation on the Effect of Environment on Water Quality of Hydropower Station Reservoir in the Endemic Area of Coal-Bearing Fluorine-Arsenic Poisoning. Bulletin of Disease Control and Prevention, No. 3, 59-60.

[17] Tang, L. (2008) Study on Transfer and Transformation of Arsenic in Coal Combustion in Southern Shaanxi. Capital Normal University, Beijing.

[18] Li, Y., Bai, A.M., Ma, C.G., Fan, Z.X. and Yang, X.D. (2009) The Survey of Arsenic and Fluoride Levels in Coal from Coal Mines in South of Shaanxi. Journal of Environment and Health, 26, 991-993.

[19] Dai, S.F., Ren, D.Y. and Chou, C.L. (2012) Geochemistry of Trace Elements in Chinese Coals: A Review of Abundances, Genetic Types, Impacts on Human Health, and Industrial Utilization. International Journal of Coal Geology, 94, 3-21. https://doi.org/10.1016/j.coal.2011.02.003

[20] Chen, B.Q., Li, J.L., Wang, Y.P., Fan, Z.X., Zheng, L.Y. and Li, Y. (1999) Investigation on the Prevalence of Coal-Burning Fluorine in Shaanxi Province. Bulletin of Disease Control and Prevention, No. 3, 42-44.

[21] Dai, S.F., Zheng, X., Wang, X.B., Robert, B.F., Jiang, Y.F., Ren, D.Y., Yan, X.Y. and Zhou, Y.P. (2017) Stone Coal in China: A Review. International Geology Review, 60, 736-753.

[22] Dai, S.F., Ian, T.G. and Colin, R.W. (2016) A Review of Anomalous Rare Earth 
Elements and Yttrium in Coal. International Journal of Coal Geology, 159, 82-95. https://doi.org/10.1016/j.coal.2016.04.005

[23] James, C.H. and Dai, S.F. (2016) Petrology and Chemistry of Sized Pennsylvania Anthracite, with Emphasis on the Distribution of Rare Earth Elements. Fuel, 185, 305-315. https://doi.org/10.1016/j.fuel.2016.07.055

[24] Zhu, L.Y. (1983) Early Paleozoic High Metamorphic Stone Coal and Rock Study and Geological Significance. Geological Review, 28, 245-261.

[25] Luo, K.L., Chen, D.L. and Ge, L.M. (1994) The Associated Minerals of the Black Rock Series and Coal Measures in the Paleozoic of Shaanxi Province. Northwest University Press, Xi'an, 1-92.

[26] Yudovich, Y. and Ketris, M.P. (2009) Estimations of Clarkes for Carbonaceous Biolithes: World Averages for Trace Element Contents in Black Shales and Coals. International Journal of Coal Geology, 78, 135-148. https://doi.org/10.1016/j.coal.2009.01.002

[27] Taylor, S.R. and McLennan, S.M. (1985) The Continental Crust: Its Composition and Evolution. Blackwell Scientific Publication, Oxford. 